\title{
Effect of lead on the sorption of phenol onto montmorillonites and organo-montmorillonites
}

\author{
Liang-guo Yan, Xiao-quan Shan*, Bei Wen, Shuzhen Zhang \\ State Key Laboratory of Environmental Chemistry and Ecotoxicology, Research Center for Eco-Environmental Sciences, Chinese Academy of Sciences, \\ P.O. Box 2871, Beijing 100085, China
}

Received 8 August 2006; accepted 11 December 2006

Available online 14 December 2006

\begin{abstract}
The effect of lead $(\mathrm{Pb})$ on the sorption of phenol onto montmorillonite-based sorbents was studied using a batch equilibration method when phenol and $\mathrm{Pb}$ were sorbed simultaneously and either $\mathrm{Pb}$ or phenol was previously sorbed. The sorbents were $\mathrm{Na}^{+}-\mathrm{Ca}^{2+}{ }_{-}, \mathrm{hexade}^{-}$ cyl trimethylammonium (HDTMA)- $\mathrm{Na}^{+}$-, and HDTMA-Ca ${ }^{2+}$-montmorillonites. Pb diminished the sorption of phenol largely onto $\mathrm{Na}^{+}-$or $\mathrm{Ca}^{2+}$-montmorillonites, while phenol had little effect on the sorption of $\mathrm{Pb}$ onto all sorbents. $\mathrm{Pb}$ had no effect on the sorption of phenol onto HDTMA-Na ${ }^{+}$- or HDTMA-Ca ${ }^{2+}$-montmorillonites either. The sorption capacity of phenol followed the order HDTMA-Na ${ }^{+}->$HDTMA-Ca ${ }^{2+}$ $>\mathrm{Na}^{+}->\mathrm{Ca}^{2+}$-montmorillonites. The pseudo-second-order equation described the kinetics of phenol sorption well. Sorption isotherms of phenol followed the Freundlich equation. Phenol sorption on HDTMA-Na ${ }^{+}$- and HDTMA-Ca ${ }^{2+}$-montmorillonites was linear, while that on Na ${ }_{-}$ and $\mathrm{Ca}^{2+}$-montmorillonites was nonlinear.
\end{abstract}

(c) 2007 Elsevier Inc. All rights reserved.

Keywords: $\mathrm{Na}^{+}{ }_{-}, \mathrm{Ca}^{2+}$, HDTMA-Na ${ }^{+}-$, and HDTMA-Ca ${ }^{2+}$-montmorillonites; Sorption; Sorption kinetics; Phenol; $\mathrm{Pb}$

\section{Introduction}

Phenol and its derivatives are common pollutants of petroleum and petrochemical and coal conversion industries. They are considered as priority pollutants since they are harmful to organisms at low concentrations.

In recent years, there has been an increasing interest in utilizing natural clay minerals and organoclays for the removal of phenol and phenolic compounds from aqueous solutions [1-7]. Banat et al. [1] examined the feasibility of using natural bentonite (mainly montmorillonite) for the sorption of phenol from aqueous solution. Treatment of clays with quaternary amine cationic surfactants could increase sorption capacity of phenol greatly [8-12]. Quaternary ammonium cations may be retained by both the outer and interlayer surfaces of an expandable clay particle via an ion-exchange, which are not easily displaced by smaller cations, such as $\mathrm{H}^{+}, \mathrm{Na}^{+}$, or $\mathrm{Ca}^{2+}$. The exchanged

\footnotetext{
* Corresponding author. Fax: +86 1062923563.

E-mail address: xiaoquan@ rcees.ac.cn (X.-q. Shan).
}

mineral surfaces become more organophilic, thus increase their sorption of nonionic organic solutes from water. Sorption of nonionic organic contaminants from water by organoclays such as hexadecyl trimethylammonium (HDTMA)-smectite was originally viewed as a partition process involving the organic cation-derived organic phase [13-17]. Sorption of phenol, $p$-nitrophenol and aniline to the synthesized dual-cation and anion-cation organobentonites was dominated by adsorption at low concentrations and by partition at high concentrations $[18,19]$.

Lead $(\mathrm{Pb})$ is one of hazardous heavy metals. It tends to be accumulated in organisms and enter the food chains. $\mathrm{Pb}$ content in the environment can be accumulated to a very high level through the application of fertilizers, sewage sludge or irrigation with wastewater. Clay minerals, such as montmorillonite, are potential adsorbents for heavy metals as they have a large specific surface area and a high cation-exchange capacity. $\mathrm{X}$-ray absorption fine structure spectroscopic study indicated that the formation of inner- and outer-sphere complexes is responsible for the adsorption of $\mathrm{Pb}$ onto montmorillonite, and the adsorption of $\mathrm{Pb}$ depended on ionic strength and $\mathrm{pH}$ [20]. 
At low ionic strength and $\mathrm{pH}$ the adsorption is primarily ascribed to the formation of outer-sphere complex and most likely occurs on the basal planes existing in the interlayer regions of the montmorillonite. As $\mathrm{pH}$ and ionic strength increases, the formation of inner-sphere complex becomes more important. It occurs on the edges of the montmorillonite and includes the formation of $\mathrm{Pb}$ polymers. The data from such study also suggested that adsorbed $\mathrm{Pb}$ existed as a mixture of inner- and outer-sphere complexes under appropriate ionic strength and $\mathrm{pH}$ conditions.

It is realized that under field conditions both heavy metals and organic chemicals may coexist. Compared with the extensive separate studies on the sorption of heavy metals and organic chemicals onto clays and organoclays, there is little information on the effect of heavy metals on the sorption of organic chemicals and vice versa [21-24]. Generally, clays are known to effectively sorb mostly heavy metals, while organoclays are adsorbents of organic contaminants. It has been assumed that there exists an optimal coverage of cationic surfactant on the clay particles to sorb both heavy metals and organic contaminants $[25,26]$.

Adsorption and desorption of $\mathrm{Cu}$ on montmorillonite were affected by the presence of a cationic pesticide chlordimeform [24]. $\mathrm{Cu}$ adsorption decreased when both adsorbates were adsorbed simultaneously, indicating a competition between $\mathrm{Cu}$ and chlordimeform for interlamellar positions. Morillo et al. $[22,23,27,28]$ studied the mutual influence of glyphosate and $\mathrm{Cu}$ adsorption on montmorillonite and soil. Glyphosate adsorption on montmorillonite decreased in the presence of $\mathrm{Cu}$ in solution. This was attributed to the formation of $\mathrm{Cu}-$ glyphosate complexes that have a lower tendency to be adsorbed on montmorillonite than the free glyphosate. These works also found that the presence of $\mathrm{Cu}$ enhanced the sorption of glyphosate on soil.

It is very important to study the sorption behaviors of heavy metals and toxic organic pollutants and the relevant mechanisms, which may help to uphold environmental standards for complex pollutants. There are few reports available in this field $[29,30]$. In the present study, $\mathrm{Pb}$ and phenol were chosen as representatives of heavy metals and toxic organic pollutants, respectively. We studied the sorption of phenol as affected by $\mathrm{Pb}$ using $\mathrm{Na}^{+}-, \mathrm{Ca}^{2+}$, HDTMA-Na ${ }_{-}^{+}$, and HDTMA-Ca ${ }^{2+}$ montmorillonites as sorbents and vice versa. The sorption kinetics was also evaluated.

\section{Materials and methods}

\subsection{Materials}

Natural montmorillonite used in this study was purchased from Beijing Youlichuangjia Science and Technology Development Company (Beijing, China). According to the supplier, the natural montmorillonite contains $98 \%$ montmorillonite, $0.5 \%$ kaolinite, and $1.0 \%$ quartz. The chemical compositions are $50.90 \% \mathrm{SiO}_{2}, 18.36 \% \mathrm{Al}_{2} \mathrm{O}_{3}, 1.03 \% \mathrm{Fe}_{2} \mathrm{O}_{3}, 3.97 \% \mathrm{CaO}$, 4.14\% $\mathrm{MgO}, 0.02 \% \mathrm{TiO}_{2}, 0.72 \% \mathrm{~K}_{2} \mathrm{O}, 1.18 \% \mathrm{Na}_{2} \mathrm{O}$, and $2.15 \% \mathrm{P}_{2} \mathrm{O}_{5}$.
All chemicals, such as phenol, $\mathrm{HDTMA}, \mathrm{Pb}\left(\mathrm{NO}_{3}\right)_{2}, \mathrm{NaNO}_{3}$, $\mathrm{NaOH}$, and $\mathrm{HNO}_{3}$ were of analytical reagent grade or better quality.

\subsection{Preparation of sorbents}

Natural montmorillonite was used just as received without further purification. A portion of $10 \mathrm{~g}$ montmorillonite was enriched with $1.0 \mathrm{~L}$ of $1.0 \mathrm{~mol} \mathrm{~L}^{-1} \mathrm{NaCl}$ or $\mathrm{CaCl}_{2}$ solution in beaker. The montmorillonite suspension was shaken for $24 \mathrm{~h}$ and fresh chloride salt solutions were used to replace the original solutions obtained after sedimentation. This process was repeated three times to ensure complete cation saturation. The excess chloride salts were removed by repeatedly washing with deionized water until chloride-free as indicated by the $\mathrm{AgNO}_{3}$ test. The product was dried at $80^{\circ} \mathrm{C}$ and gently ground in an agate mortar. Such treated montmorillonites were designated as $\mathrm{Na}^{+}$- and $\mathrm{Ca}^{2+}$-montmorillonites.

The organo-montmorillonites were prepared by adding $10 \mathrm{~g}$ $\mathrm{Na}^{+}$- or $\mathrm{Ca}^{2+}$-montmorillonite to $1.0 \mathrm{~L}$ appropriate amount of HDTMA solution in a 1:1 molar ratio to their CEC (89.6 cmol kg${ }^{-1}$ for $\mathrm{Na}^{+}$-montmorillonite and $72.4 \mathrm{cmol} \mathrm{kg}^{-1}$ for $\mathrm{Ca}^{2+}$-montmorillonite), respectively. The mixtures were subjected to a mechanical stirring for $24 \mathrm{~h}$. The suspensions were then separated by centrifugation, washed with deionized water several times until no $\mathrm{Br}^{-}$was detected from the supernatant and dried at $80^{\circ} \mathrm{C}$. The two prepared sorbents were designated as HDTMA-Na ${ }^{+}$- and HDTMA-Ca ${ }^{2+}$-montmorillonites.

\subsection{Effect of $\mathrm{pH}$ on the sorption of phenol}

Phenol was dissolved in $0.01 \mathrm{molL}^{-1} \mathrm{NaNO}_{3} / 0.1 \mathrm{~g} \mathrm{~L}^{-1}$ $\mathrm{NaN}_{3}$ solutions for the sorption experiment of $\mathrm{Na}^{+}-$and HDTMA-Na ${ }^{+}$-montmorillonites, and in a $0.01 \mathrm{~mol} \mathrm{~L}^{-1} \mathrm{Ca}-$ $\left(\mathrm{NO}_{3}\right)_{2} / 0.1 \mathrm{~g} \mathrm{~L}^{-1} \mathrm{NaN}_{3}$ solution for the sorption experiment of $\mathrm{Ca}^{2+}$ - and HDTMA-Ca ${ }^{2+}$-montmorillonites. The batch sorption equilibration was done in triplicate in $50-\mathrm{ml}$ glass centrifuge tubes by mixing $0.400 \mathrm{~g} \mathrm{Na}^{+}$-montmorillonite (or $\mathrm{Ca}^{2+}$ montmorillonite) or $0.100 \mathrm{~g}$ HDTMA- $\mathrm{Na}^{+}$- (or HDTMA$\mathrm{Ca}^{2+}$-montmorillonite) with $20 \mathrm{ml} 10.0 \mathrm{mmol} \mathrm{L}^{-1}$ phenol solutions. Due to the large sorption ability of HDTMA-Na ${ }^{+}$or HDTMA-Ca ${ }^{2+}$-montmorillonite, only 0.100 g HDTMA-Na ${ }^{+}-$ or HDTMA-Ca ${ }^{2+}$-montmorillonite was used in this study. The $\mathrm{pH}$ was adjusted from 3.0 to 12.0 by addition of $0.1 \mathrm{~mol} \mathrm{~L}^{-1}$ $\mathrm{HNO}_{3}$ or $0.1 \mathrm{~mol} \mathrm{~L}^{-1} \mathrm{NaOH}$. The suspension was shaken by end-over-end continuously for $24 \mathrm{~h}$ at room temperature. During the shaking, the $\mathrm{pH}$ values were measured at certain intervals and readjusted if necessary. The suspension was centrifuged at $1667 \mathrm{~g}$ for $20 \mathrm{~min}$ to separate liquid and solid phases, and then a portion of supernatant was used for spectrophotometric determination of phenol at $269.5 \mathrm{~nm}$.

\subsection{Sorption kinetics of phenol}

Sorption kinetics was performed by a batch equilibration method at room temperature. Briefly, $0.100 \mathrm{~g}$ of HDTMA- $\mathrm{Na}^{+}-$ 
or HDTMA-Ca ${ }^{2+}$-montmorillonite or $0.400 \mathrm{~g}$ of $\mathrm{Na}^{+}$- or $\mathrm{Ca}^{2+}$ montmorillonite with $20 \mathrm{ml}$ of phenol solutions was added to 50-ml glass centrifuge tubes sealed by Teflon-lined screw caps. The $\mathrm{pH}$ value of the system was kept at 6.0. The initial phenol concentration added was 10.0 or $4.0 \mathrm{mmol} \mathrm{L}^{-1}$. After the suspension was shaken by end-over-end for the target contact time, the suspension was centrifuged. The sorbed phenol was measured by the differences between the initial and final phenol concentrations in the equilibrium solutions. The sorption kinetic experiments were performed in triplicate.

\subsection{Sorption isotherms of phenol}

The experiments were carried out in triplicate by mixing $0.100 \mathrm{~g}$ of HDTMA-Na ${ }^{+}$- or HDTMA-Ca ${ }^{2+}$-montmorillonite or $0.400 \mathrm{~g}$ of $\mathrm{Na}^{+}$- or $\mathrm{Ca}^{2+}$-montmorillonite with $20 \mathrm{ml}$ of various concentrations of phenol in $0.01 \mathrm{~mol} \mathrm{~L}^{-1} \mathrm{NaNO}_{3}$ (or Ca$\left.\left(\mathrm{NO}_{3}\right)_{2}\right) / 0.1 \mathrm{~g} \mathrm{~L}^{-1} \mathrm{NaN}_{3}$ background electrolyte solution. The $\mathrm{pH}$ of phenol-sorbent suspension was adjusted to 6.0. The $\mathrm{pH}$ value was measured at certain intervals and readjusted if necessary. The suspension was shaken by end-over-end continuously for $24 \mathrm{~h}$ to ensure complete sorption.

\subsection{Effect of $\mathrm{Pb}$ on the sorption of phenol}

The batch equilibration sorption experiments were carried out in triplicate by mixing $0.100 \mathrm{~g}$ of HDTMA- $\mathrm{Na}^{+}-$ or HDTMA-Ca ${ }^{2+}$-montmorillonite or $0.400 \mathrm{~g} \mathrm{Na}^{+}-$or $\mathrm{Ca}^{2+}$ montmorillonite with $20 \mathrm{ml} 0.01 \mathrm{~mol} \mathrm{~L}^{-1} \mathrm{NaNO}_{3}$ (or Ca$\left.\left(\mathrm{NO}_{3}\right)_{2}\right) / 0.1 \mathrm{~g} \mathrm{~L}^{-1} \mathrm{NaN}_{3}$ solution containing various concentrations of phenol and $\mathrm{Pb}\left(0,0.5,1.0\right.$, and $\left.2.0 \mathrm{mmol} \mathrm{L}^{-1}\right)$ in $50-\mathrm{ml}$ glass centrifuge tubes sealed by Teflon-lined screw caps. The $\mathrm{pH}$ of suspensions was adjusted to 6.0. The suspensions were shaken by end-over-end continuously for $24 \mathrm{~h}$ at room temperature. After centrifugation at $1667 \mathrm{~g}$ for $20 \mathrm{~min}$, phenol and $\mathrm{Pb}$ in the supernatant were determined, respectively. The concentrations of $\mathrm{Pb}$ were determined by inductively coupled plasmaatomic emission spectrometry (ICP-AES, OPTIMA2000DV, Perkin-Elmer, USA).

Effect of $\mathrm{Pb}$ on the sorption of phenol was also conducted when either phenol or $\mathrm{Pb}$ was previously sorbed. The procedure outlined above for simultaneous sorption of both sorbates was followed. The only exception was that either $\mathrm{Pb}$ or phenol was previously sorbed for $24 \mathrm{~h}$, and then the suspension was shaken for extra $24 \mathrm{~h}$ again after the solution containing various concentrations of phenol or $\mathrm{Pb}$ was added.

\subsection{Sorption isotherms of $\mathrm{Pb}$ in the absence or presence of phenol}

A portion of $0.100 \mathrm{~g}$ of $\mathrm{Na}^{+}-$or $\mathrm{Ca}^{2+}{ }_{-}$-montmorillonite or HDTMA-Na ${ }^{+}$- or HDTMA-Ca ${ }^{2+}$-montmorillonite with $20 \mathrm{ml}$ of various concentrations of $\mathrm{Pb}$ in the absence and presence of $10.0 \mathrm{mmol} \mathrm{L}^{-1}$ phenol in $0.01 \mathrm{~mol} \mathrm{~L}^{-1} \mathrm{NaNO}_{3} / 0.1 \mathrm{~g} \mathrm{~L}^{-1}$ $\mathrm{NaN}_{3}$ (or $\mathrm{Ca}\left(\mathrm{NO}_{3}\right)_{2} / 0.1 \mathrm{~g} \mathrm{~L}^{-1} \mathrm{NaN}_{3}$ ) background electrolyte solution was added together to glass centrifuge tubes. The $\mathrm{pH}$ of all sorbate-sorbent solutions was adjusted to 6.0. The sorption equilibration time was $24 \mathrm{~h}$. After reaching equilibrium the suspensions were centrifuged at $1667 \mathrm{~g}$ for $20 \mathrm{~min}$ to separate liquid and solid phases, and then $\mathrm{Pb}$ in supernatants was determined by ICP-AES. The sorption experiments were carried out in triplicate.

\subsection{Sorption models}

\subsubsection{Sorption kinetics models}

The kinetics of sorption is important from the point of view that it controls the sorption efficiency. Two kinetics models, pseudo-first- and pseudo-second-order equations, were applied to our experimental data.

A simple kinetic analysis of sorption is the pseudo-firstorder equation in the form [31]:

$\lg \left(q_{\mathrm{e}}-q_{\mathrm{t}}\right)=\lg q_{\mathrm{e}}-\frac{k_{1}}{2.303} t$,

where $q_{\mathrm{t}}\left(\mathrm{mmol} \mathrm{kg}^{-1}\right)$ is the amount of sorbed at time $t(\mathrm{~h})$, $q_{\mathrm{e}}\left(\mathrm{mmol} \mathrm{kg}^{-1}\right)$ is the amount of sorbed at equilibrium, and $k_{1}$ $(1 / h)$ is the rate constant of the first-order sorption.

The sorption kinetics may also be described by a pseudosecond-order reaction [31]. The linear form of this model is

$\frac{t}{q_{\mathrm{t}}}=\frac{1}{k_{2} q_{\mathrm{e}}^{2}}+\frac{1}{q_{\mathrm{e}}} t$,

where $k_{2}\left(\mathrm{~kg} \mathrm{mmol}^{-1} \mathrm{~h}^{-1}\right)$ is the rate constant of pseudosecond-order sorption.

\subsubsection{Sorption isotherms models}

The widely used equilibrium-based isotherm models are Freundlich and Langmuir equations. Their linear forms are listed below:

$\ln q_{\mathrm{e}}=n \ln C_{\mathrm{e}}+\ln K_{\mathrm{f}}$,

$\frac{C_{\mathrm{e}}}{q_{\mathrm{e}}}=\frac{1}{b q_{\mathrm{m}}}+\frac{C_{\mathrm{e}}}{q_{\mathrm{m}}}$,

where $q_{\mathrm{e}}\left(\mathrm{mmol} \mathrm{kg}^{-1}\right)$ is the amount of sorption, $C_{\mathrm{e}}\left(\mathrm{mmol} \mathrm{L}^{-1}\right)$ is the equilibrium concentration; $n$ is a constant indicating the Freundlich isotherm curvature, and $K_{\mathrm{f}}\left(\left(\mathrm{mmol} \mathrm{kg}^{-1}\right) /\right.$ $\left.\left(\mathrm{mmol} \mathrm{L}^{-1}\right)^{n}\right)$ is the Freundlich sorption coefficients; $q_{\mathrm{m}}$ $\left(\mathrm{mmol} \mathrm{kg}^{-1}\right)$ is the maximum adsorption capacity of Langmuir, $b$ is Langmuir constants.

\section{Results and discussion}

\subsection{Effect of $p H$ on phenol sorption}

The sorption of phenol by $\mathrm{Na}^{+}-, \mathrm{Ca}^{2+}-$, HDTMA-Na ${ }^{+}$, and HDTMA-Ca ${ }^{2+}$-montmorillonites was studied at various $\mathrm{pH}$ levels. As shown in Fig. 1, the sorption capacities of phenol showed no systematic variations between $\mathrm{pH} 3.0$ and 10.0, while it declined dramatically between 10.0 and 12.0. This observation is consistent with Juang et al. [2], Li et al. [32], and Yang et al. [11]. However, phenol sorption to montmorillonite, kaolinite, and organobentonite decreased when $\mathrm{pH}$ was higher 


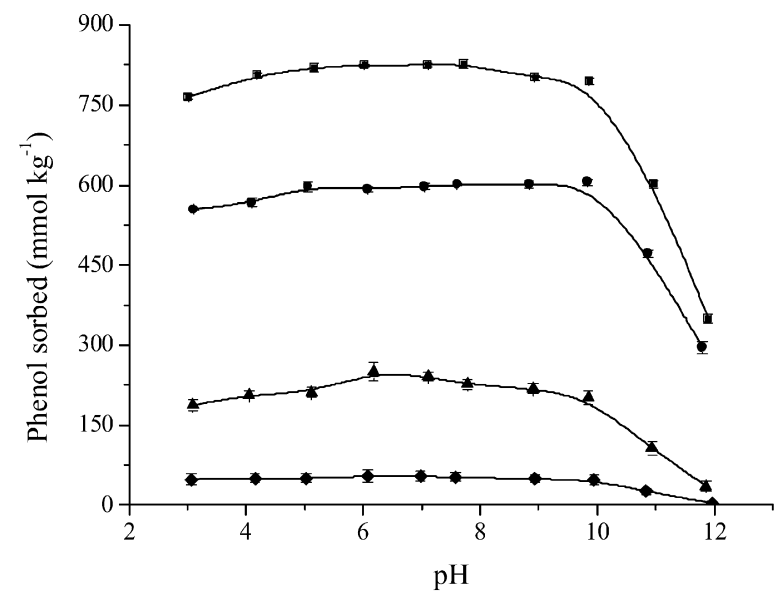

Fig. 1. Effect of equilibrium solution $\mathrm{pH}$ on the sorption of phenol on

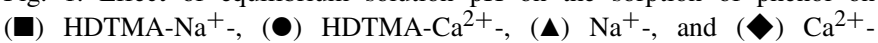
montmorillonites.

than $8[1,3,33]$, and to organo-montmorillonite increased when $\mathrm{pH}$ was higher than its $\mathrm{p} K_{\mathrm{a}} 9.89$ [4,34]. It seems that the extent of sorption of phenol to montmorillonites varies as a function of solution $\mathrm{pH}$, since $\mathrm{pH}$ governs both the fraction of phenol in deprotonated form and charges of sorbent surfaces. Phenol is present in neutral form when $\mathrm{pH}$ was lower than 2 units of its $\mathrm{p} K_{\mathrm{a}}$ 9.89. When $\mathrm{pH}$ was higher than 2 units of its $\mathrm{p} K_{\mathrm{a}} 9.89$, deprotonated phenol is predominated. At higher $\mathrm{pH}$, the decreased phenol sorption may be caused by the electrostatic repulsion between the reactive surface sites and the negatively charged phenol molecules $[11,30]$. Moreover, the sorbent is a key factor since the charge density on a given solid is dependent on the surrounding conditions. Solution ionic strength and composition also affect the sorption of phenol.

\subsection{Sorption kinetics of phenol}

The results of the sorption kinetics experiments are presented in Fig. 2. The plots represent the amount of phenol sorbed $q_{\mathrm{t}}$ onto montmorillonites versus time $t$. For an initial phenol concentration of $10 \mathrm{mmol} \mathrm{L}^{-1}$, it was shown that the equilibrium time was almost $18 \mathrm{~h}$ for all types of montmorillonites. However, the equilibrium time was slightly different for the initial concentration of $4.0 \mathrm{mmol} \mathrm{L}^{-1}$. The decrease in initial phenol concentration influenced the contact time necessary to reach equilibrium and decreased the sorption capacity on $\mathrm{Na}^{+}, \mathrm{Ca}^{2+}$, , HDTMA-Na ${ }_{-}$, and HDTMA-Ca ${ }^{2+}-$ montmorillonites, respectively. In order to ensure equilibrium, the subsequent experiments were performed for $24 \mathrm{~h}$.

Many studies have pointed out that the majority of sorption kinetics can be represented as a pseudo-first-order rate mechanism [35]. A detailed sorption studies on the phenol and three chlorophenols by carbonaceous adsorbent have indicated that the sorption process is a first-order kinetics and is pore diffusion control [36]. Akçay [37] found that the sorption rate of $p$-chlorophenol by organophilic bentonite fit the pseudo-firstorder kinetics. However, it was clearly found that the pseudosecond-order equation, which agrees with chemisorption as the rate-control mechanism, was able to better describe the sorption

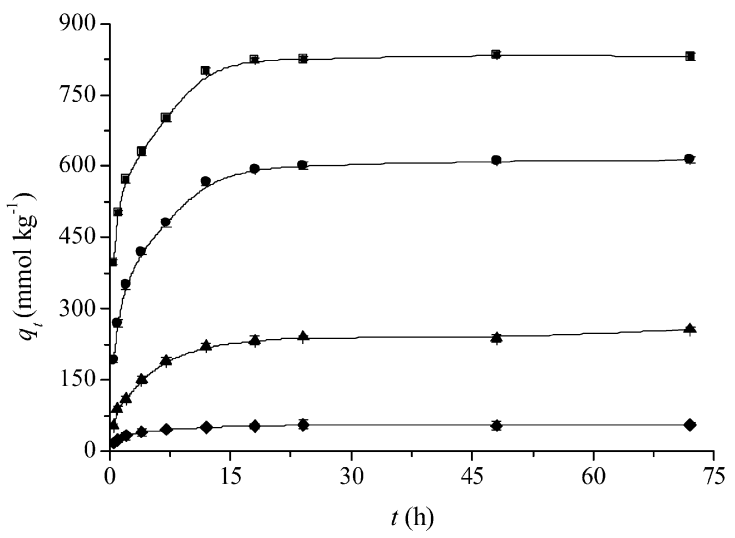

(a)

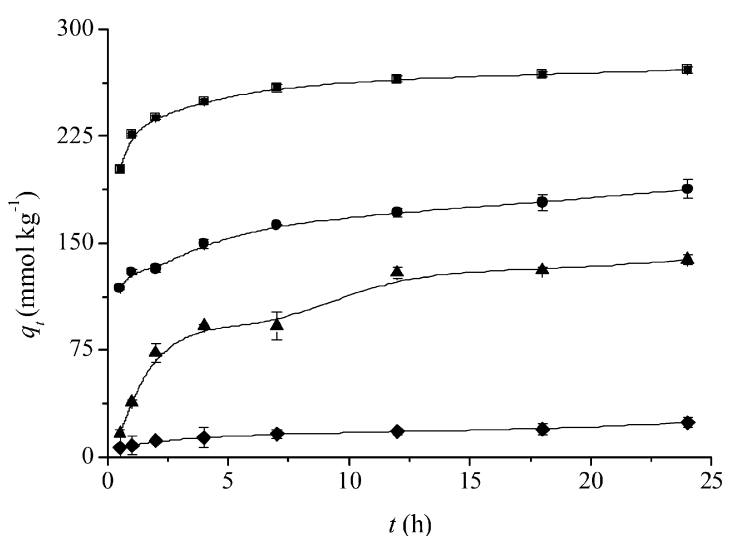

(b)

Fig. 2. Sorption kinetics of phenol for (ם) HDTMA-Na ${ }_{-}^{+}$, (•) HDTMA-Ca ${ }^{2+}-,(\boldsymbol{\Delta}) \mathrm{Na}^{+}$-, and $\left(\boldsymbol{C ^ { 2 }} \mathrm{Ca}^{2+}\right.$-montmorillonites. The initial phenol concentrations were $10 \mathrm{mmol} \mathrm{L}^{-1}$ (a) and $4.0 \mathrm{mmol} \mathrm{L}^{-1}$ (b).

of phenolic compounds onto organoclays $[2,6,38]$ and other sorbents $[39,40]$.

To evaluate the differences in the sorption kinetics rate, the kinetics of phenol sorption was described with pseudofirst- and pseudo-second-order models. The kinetics data are plotted as the linear form of the models (Fig. 3), and the resultant parameters are given in Table 1. By comparing the amount of phenol sorbed $q_{\mathrm{e}}$ at equilibrium, the following order is observed: HDTMA-Na ${ }_{-}^{+}>$HDTMA-Ca ${ }^{2+}$ $>\mathrm{Na}^{+}{ }_{-}>\mathrm{Ca}^{2+}$-montmorillonites. The rate constant $k_{1}$ of pseudo-first-order sorption and $k_{2}$ of pseudo-second-order sorption ranged from 0.07478 to $0.2739 \mathrm{~h}^{-1}$ and $9.629 \times 10^{-4}$ to $3.367 \mathrm{~kg} \mathrm{mmol}^{-1} \mathrm{~h}^{-1}$, respectively. The correlation coefficients of the linear fit are all higher than 0.97 with $99 \%$ confidence level (Table 1). As shown in Fig. 3 and Table 1, whatever the kinetic equation used, the description of the sorption kinetics was satisfactory.

The validity of the pseudo-first- and pseudo-second-order equations can be checked by studying the kinetics under different initial concentrations, because in the case of a first-order kinetic reaction, the half-life time is constant whatever the initial sorbate concentration [41]. The initial concentration of phenol was varied from 10 to $4.0 \mathrm{mmol} \mathrm{L}^{-1}$, as shown in Fig. 2 . Furthermore, the calculated half-life time based on $k_{1}$ values (Table 1) decreased from 3.1, 6.7, 3.0, and 4.4 to $2.8,3.8$, 


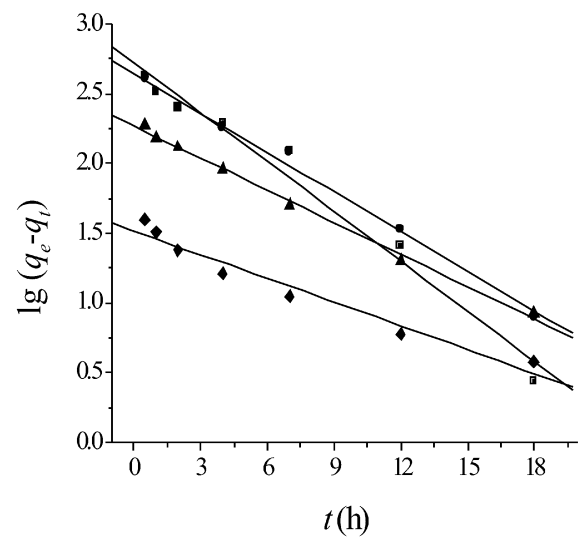

(a)

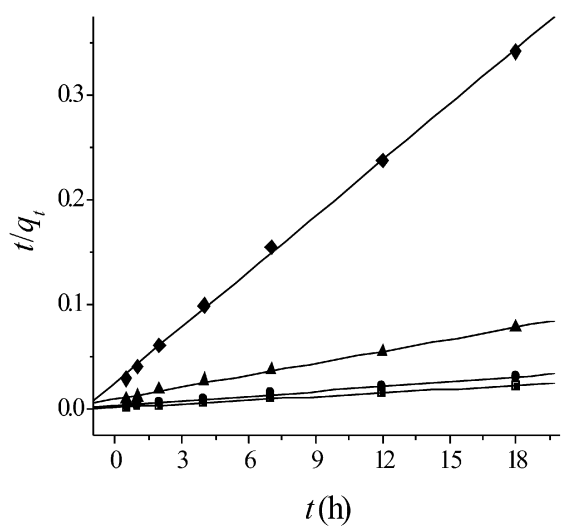

(c)

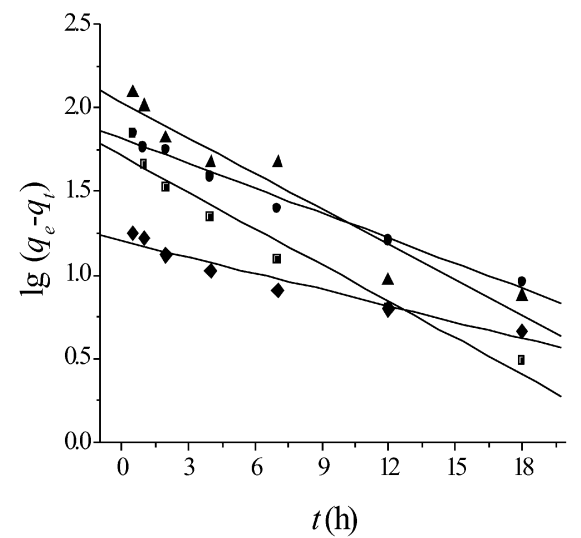

(b)

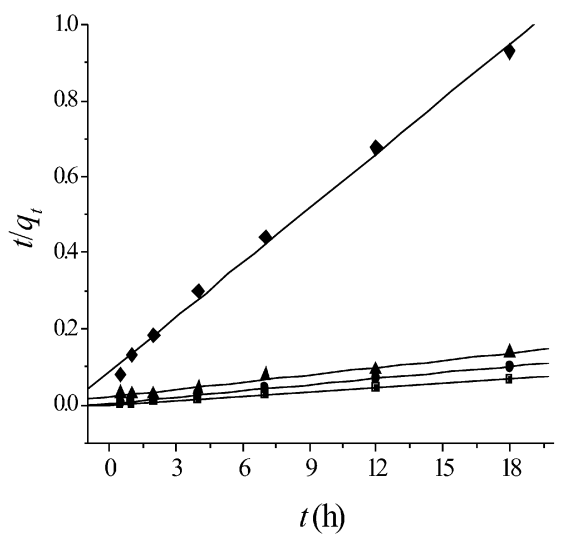

(d)

Fig. 3. Pseudo-first- (a, b) and pseudo-second-order equation (c, d) fit of phenol sorption on (ם) HDTMA-Na ${ }^{+}$, $\mathrm{Ca}^{2+}$-montmorillonites. The initial phenol concentrations were $10 \mathrm{mmol} \mathrm{L}^{-1}(\mathrm{a}, \mathrm{c})$ and $4.0 \mathrm{mmol} \mathrm{L}^{-1}(\mathrm{~b}, \mathrm{~d})$.

Table 1

Kinetics parameters and correlation coefficients for the sorption of phenol

\begin{tabular}{|c|c|c|c|c|c|c|c|}
\hline \multirow[t]{2}{*}{ Sorbent } & \multirow{2}{*}{$\begin{array}{l}C_{0} \\
\left(\mathrm{mmol} \mathrm{L}^{-1}\right)\end{array}$} & \multicolumn{3}{|c|}{ Pseudo-first-order equation } & \multicolumn{3}{|c|}{ Pseudo-second-order equation } \\
\hline & & $q_{\mathrm{e}}\left(\mathrm{mmol} \mathrm{kg}^{-1}\right)$ & $k_{1}\left(\mathrm{~h}^{-1}\right)$ & $R^{2}$ & $q_{\mathrm{e}}\left(\mathrm{mmol} \mathrm{kg}^{-1}\right)$ & $k_{2}\left(\mathrm{~kg} \mathrm{mmol}^{-1} \mathrm{~h}^{-1}\right)$ & $R^{2}$ \\
\hline \multirow[t]{2}{*}{$\mathrm{Na}^{+}-\mathrm{Mt}^{\mathrm{a}}$} & 10 & 184.3 & 0.1769 & $0.9979^{\mathrm{b}}$ & 261.1 & $1.614 \times 10^{-3}$ & $0.9981^{\mathrm{b}}$ \\
\hline & 4.0 & 107.9 & 0.1636 & $0.9632^{\mathrm{b}}$ & 156.7 & 3.367 & $0.9892^{b}$ \\
\hline \multirow[t]{2}{*}{$\mathrm{Ca}^{2+}-\mathrm{Mt}^{\mathrm{a}}$} & 10 & 32.70 & 0.1306 & $0.9789^{b}$ & 56.37 & $1.262 \times 10^{-2}$ & $0.9996^{\mathrm{b}}$ \\
\hline & 4.0 & 15.97 & 0.07478 & $0.9724^{\mathrm{b}}$ & 20.88 & 1.809 & $0.9980^{\mathrm{b}}$ \\
\hline \multirow[t]{2}{*}{ HDTMA-Na ${ }^{+}-\mathrm{Mt}^{\mathrm{a}}$} & 10 & 528.7 & 0.2739 & $0.9873^{\mathrm{b}}$ & 862.1 & $1.170 \times 10^{-3}$ & $0.9984^{\mathrm{b}}$ \\
\hline & 4.0 & 51.44 & 0.1673 & $0.9797^{\mathrm{b}}$ & 271.7 & 0.2594 & $0.9999^{b}$ \\
\hline \multirow[t]{2}{*}{ HDTMA-Ca ${ }^{2+}-\mathrm{Mt}^{\mathrm{a}}$} & 10 & 439.1 & 0.2174 & $0.9965^{\mathrm{b}}$ & 636.9 & $9.629 \times 10^{-4}$ & $0.9980^{\mathrm{b}}$ \\
\hline & 4.0 & 65.52 & 0.1148 & $0.9915^{\mathrm{b}}$ & 182.5 & 0.6149 & $0.9992^{b}$ \\
\hline
\end{tabular}

a Mt, montmorillonite.

b Indicates the statistical significance at probability level of $p<0.01$.

1.8, and $2.3 \mathrm{~h}$ on $\mathrm{Na}^{+}-, \mathrm{Ca}^{2+}{ }_{-}$, HDTMA-Na ${ }^{+}$, and HDTMA$\mathrm{Ca}^{2+}$-montmorillonites when the initial phenol concentration improved from 4.0 to $10 \mathrm{mmol} \mathrm{L}^{-1}$. Thus the sorption of phenol seemed to be best described by the pseudo-second-order equation. The tendency of the pseudo-first-order equation underestimated the quantity of the phenol sorption.

\subsection{Sorption isotherms of phenol}

Sorption isotherms of phenol from water by HDTMA-Na ${ }^{+}$, HDTMA- $\mathrm{Ca}^{2+}{ }_{-}, \mathrm{Na}^{+}-$, and $\mathrm{Ca}^{2+}{ }_{-}$montmorillonites were per- formed. The equilibrium sorption data were evaluated by Langmuir and Freundlich models.

The linear plots of phenol sorption on montmorillonites and the resulted parameters are shown in Fig. 4 and Table 2, respectively. It is found that the best fitting was obtained by the Freundlich model ( $R^{2}>0.96$ with $99 \%$ confidence level). This is in agreement with other works on the sorption of phenolic pollutants by clays and organoclays $[4,5,8,9,38]$. When the Langmuir model was applied to these data, a good fit was obtained on the sorption of phenol by homoionic montmorillonites. How- 
Table 2

Freundlich and Langmuir constants and correlation coefficients for the sorption of phenol

\begin{tabular}{|c|c|c|c|c|c|}
\hline Model & Parameter & $\mathrm{Na}^{+}-\mathrm{Mt}^{\mathrm{a}}$ & $\mathrm{Ca}^{2+}-\mathrm{Mt}^{\mathrm{a}}$ & 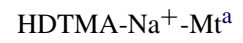 & HDTMA-Ca ${ }^{2+}-\mathrm{Mt}^{\mathrm{a}}$ \\
\hline Freundlich & $k_{\mathrm{f}}^{\mathrm{b}}$ & 66.89 & 15.85 & 99.30 & 62.50 \\
\hline \multirow[t]{2}{*}{ equation } & $n$ & 0.6128 & 0.5556 & 1.181 & 1.1099 \\
\hline & $R^{2}$ & $0.9964^{\mathrm{c}}$ & $0.9663^{c}$ & $0.9941^{\mathrm{c}}$ & $0.9768^{c}$ \\
\hline Langmuir & $q_{\mathrm{m}}\left(\mathrm{mmol} \mathrm{kg}^{-1}\right)$ & 480.8 & 78.19 & -2417 & -1483 \\
\hline \multirow[t]{2}{*}{ equation } & $b\left(\mathrm{~L} \mathrm{mmol}^{-1}\right)$ & 0.1347 & 2.276 & -0.04136 & -0.03919 \\
\hline & $R^{2}$ & $0.9569^{\mathrm{c}}$ & $0.9857^{\mathrm{c}}$ & 0.7217 & 0.6759 \\
\hline
\end{tabular}

\footnotetext{
a Mt, montmorillonite.

b $\left(\mathrm{mmol} \mathrm{kg}^{-1}\left(\mathrm{mmol} \mathrm{L}^{-1}\right)^{-n}\right)$.

c Indicates the statistical significance at probability level of $p<0.01$.
}

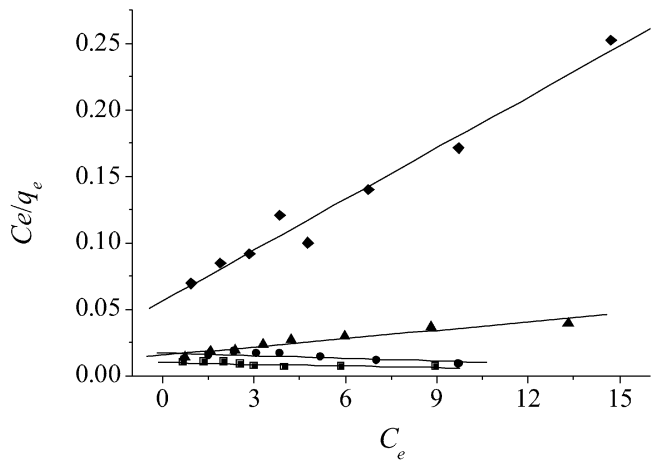

(a)

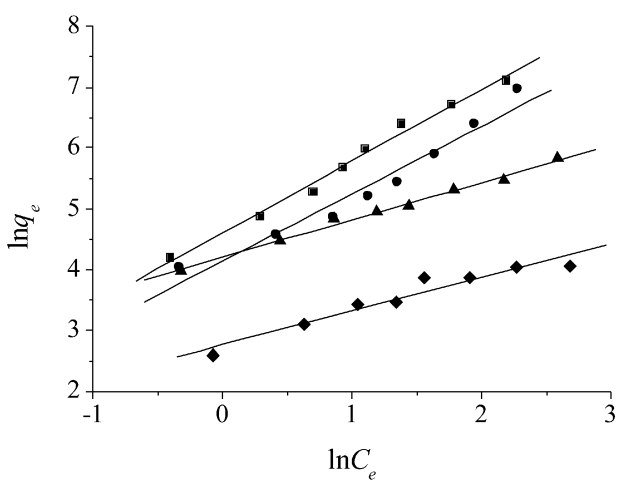

(b)

Fig. 4. Langmuir (a) and Freundlich (b) equation fit of phenol sorption onto (ם) HDTMA-Na ${ }_{-}^{+},(\bullet)$ HDTMA-Ca ${ }^{2+}-,(\boldsymbol{\Delta}) \mathrm{Na}^{+}-$, and $(\bullet) \mathrm{Ca}^{2+}$ montmorillonites.

ever, deviations of the linear fit were observed on the sorption by HDTMA-Na ${ }^{+}$- and HDTMA-Ca ${ }^{2+}$-montmorillonites. Freundlich model seemed to be more appropriate than Langmuir model.

The Freundlich constant $n$ is also a measure of the deviation from linearity of the sorption. With $1.05>n>0.95$, the sorption is practically considered linear. This means that the sorption sites are homogeneous in energy and no interaction occurs between the adsorbed species; when $n<1$, the isotherm is concave downward and implies that added sorbates are bound with weaker and weaker free energies; finally, when $n>1$, the isotherm is convex upward and infers that more sorbate presence in the sorbent enhances the free energies of further sorption [42].
The sorption isotherms (Fig. 4) and $n$ values (Table 2) indicate that partition is apparently the dominant mechanism for phenol sorption by HDTMA-Na ${ }^{+}$and HDTMA-Ca ${ }^{2+}$. montmorillonites. Here, the high degree of sorption into the HDTMA phase substantially changed the composition of the phase. This caused the solvency (i.e., the solubilization capability) of HDTMA phase for phenol to increase, so that the isotherms became convex to the abscissa. A similar phenomenon was observed for the partition of trichloroethylene and chlorobenzene by HDTMA-clays [43]. On the other hand, phenol sorption by homoionic montmorillonites is due to specific sorption to the negatively charged surface of clays and the sorption capacity is much lower than that by partition to HDTMAmontmorillonites.

Sorption was affected by the type of exchanged cations on montmorillonite (Table 2). Between the cations tested, $\mathrm{Na}^{+}$- and HDTMA-Na ${ }^{+}$-montmorillonites were much more effective than the corresponding $\mathrm{Ca}^{2+}$ - and HDTMA-Ca ${ }^{2+}$. montmorillonites for phenol sorption. The comparatively lower sorption by $\mathrm{Ca}^{2+}$-montmorillonite is attributed to the larger enthalpy of hydration of $\mathrm{Ca}^{2+}$ as compared with $\mathrm{Na}^{+}$. Larger hydration sphere around $\mathrm{Ca}^{2+}$ obscured a greater portion of the neutral siloxane surface, thereby reducing hydrophobic interactions between these surfaces and phenol [44]. For HDTMA-exchanged montmorillonites, $\mathrm{Na}^{+}$-montmorillonite sorbed more HDTMA than $\mathrm{Ca}^{2+}$-montmorillonite due to its higher CEC (89.6 $\mathrm{cmol} \mathrm{kg}^{-1}$ for $\mathrm{Na}^{+}$-montmorillonite and $72.4 \mathrm{cmol} \mathrm{kg}^{-1}$ for $\mathrm{Ca}^{2+}$-montmorillonite), thus more phenol was partitioned into the surfactant derived organic matter.

\subsection{Effect of $\mathrm{Pb}$ on phenol sorption}

Effect of $\mathrm{Pb}$ on the sorption of phenol was evaluated when both sorbates were sorbed simultaneously on $\mathrm{Na}^{+}$and $\mathrm{Ca}^{2+}$-montmorillonites and the corresponding HDTMAexchanged montmorillonites (Fig. 5). For $\mathrm{Na}^{+}-$and $\mathrm{Ca}^{2+}$ montmorillonites the sorption of phenol decreased clearly when $1.0 \mathrm{mmol} \mathrm{L}^{-1} \mathrm{~Pb}$ was added simultaneously. In contrast, $\mathrm{Pb}$ had almost insignificant effect on the sorption of phenol on HDTMA-Na ${ }^{+}$- and HDTMA-Ca ${ }^{2+}$-montmorillonites. Compared with homoionic montmorillonites, HDTMA-montmorillonites sorbed more phenol due to its surfactant derived organic matter. When $\mathrm{Pb}$ was added, it was sorbed on the surface of 


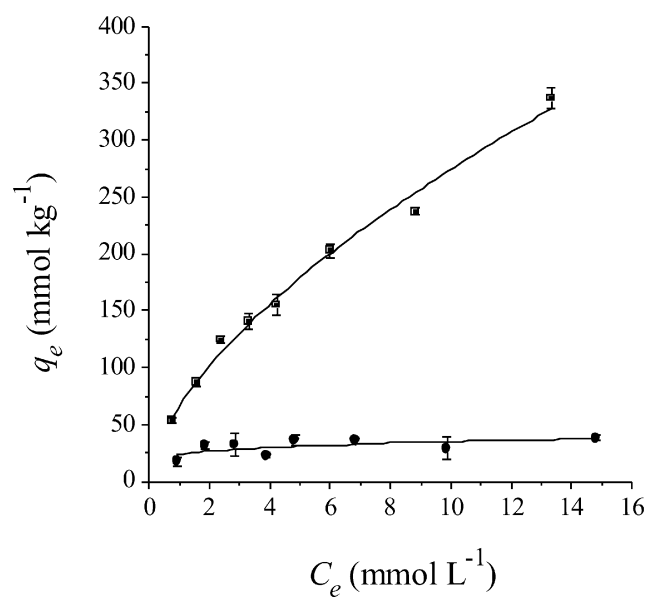

(a)

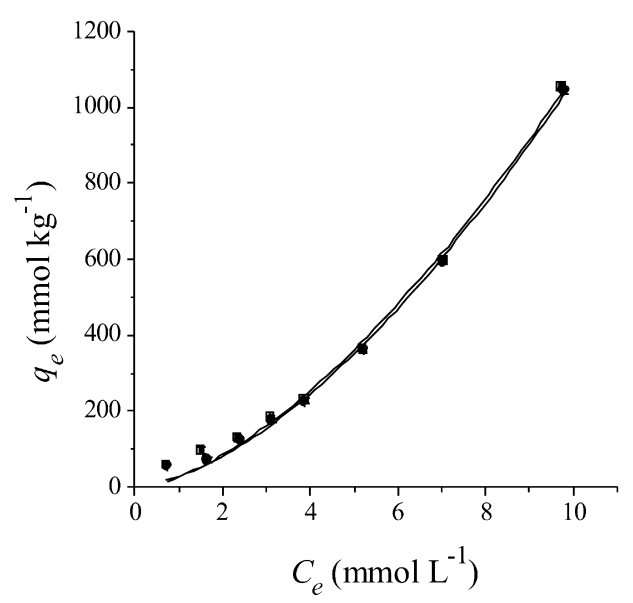

(c)

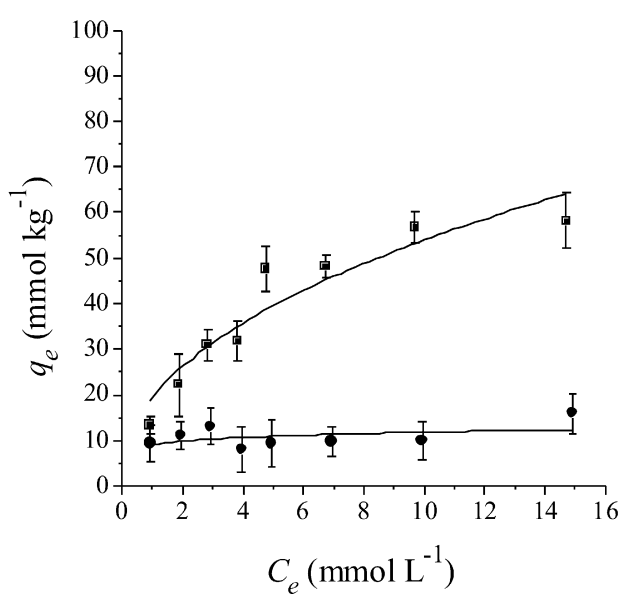

(b)

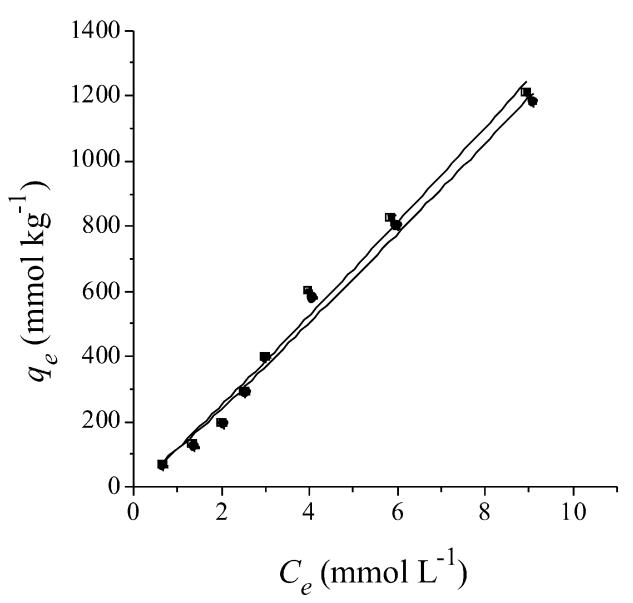

(d)

Fig. 5. Sorption isotherms of phenol onto (a) $\mathrm{Na}^{+}$, , (b) $\mathrm{Ca}^{2+}-$, (c) HDTMA-Ca ${ }^{2+}$, and (d) HDTMA-Na ${ }_{-}^{+}$-montmorillonites in the absence ( of $\mathrm{Pb}$.

HDTMA-Na ${ }^{+}$- and HDTMA-Ca ${ }^{2+}$-montmorillonites, while phenol was partitioned into surfactant derived organic matter, indicating that they were sorbed by different domains. In order to determine $\mathrm{Pb}$ remaining in solid phase its concentration in the supernatant solution was also determined simultaneously. However, the sorbed $\mathrm{Pb}$ on solid-phase sorbents varied slightly. Obviously, $\mathrm{Pb}$ sorption was independent on the presence of phenol, suggesting the higher affinity of lead for the sorbents.

To determine the effect of $\mathrm{Pb}$ on the sorption of phenol onto homoionic montmorillonites, a series of experiments were conducted. Figs. $6 \mathrm{a}$ and $6 \mathrm{~b}$ show the sorption isotherms of phenol on $\mathrm{Na}^{+}$- and $\mathrm{Ca}^{2+}$-montmorillonites when phenol and different $\mathrm{Pb}$ concentrations $\left(0,0.5,1.0\right.$, and $\left.2.0 \mathrm{mmol} \mathrm{L}^{-1}\right)$ were sorbed simultaneously. The sorbed phenol decreased with increasing $\mathrm{Pb}$ concentrations from 0 to $2.0 \mathrm{mmol} \mathrm{L}^{-1}$, suggesting that $\mathrm{Pb}$ decreased the sorption of phenol. The effect of $\mathrm{Pb}$ on the sorption of phenol was also conducted when phenol or $\mathrm{Pb}$ was previously sorbed. The sorbents were equilibrated with phenol first for $24 \mathrm{~h}$, and then a certain amount of $\mathrm{Pb}$ solution was added to the equilibrated suspension to make the initial $\mathrm{Pb}$ concentrations of $0.5,1.0$, and $2.0 \mathrm{mmol} \mathrm{L}^{-1}$, respectively. The suspension was further equilibrated for an additional $24 \mathrm{~h}$. The results are shown in Figs. 6e and 6f. Figs. $6 \mathrm{c}$ and $6 \mathrm{~d}$ show the sorption isotherms of phenol when $\mathrm{Pb}$ was previously sorbed. These results indicated that the suppression effect of $\mathrm{Pb}$ on the phenol sorption was quite similar to that when both sorbates were sorbed simultaneously (Figs. 6a and 6b). This is due to the fact that $\mathrm{Pb}$ with positive charge has stronger sorption affinity than phenol for sorption sites of montmorillonites. The results suggested that $\mathrm{Pb}$ was able to compete with phenol for the same sorption sites, even when phenol was previously sorbed. This implies that the addition of $\mathrm{Pb}$ would release the sorbed phenol from clays, and this phenomenon has its important environmental consequence.

\subsection{Sorption isotherms of $\mathrm{Pb}$ in the absence or presence of phenol}

Sorption of $\mathrm{Pb}$ in the absence and presence of $10.0 \mathrm{mmol} \mathrm{L}^{-1}$ phenol was performed. The sorption data were analyzed by a linear fit of the Freundlich and Langmuir isotherm models (Table 3). They fit the Freundlich and Langmuir equations well with correlation coefficients higher than 0.93 ex- 


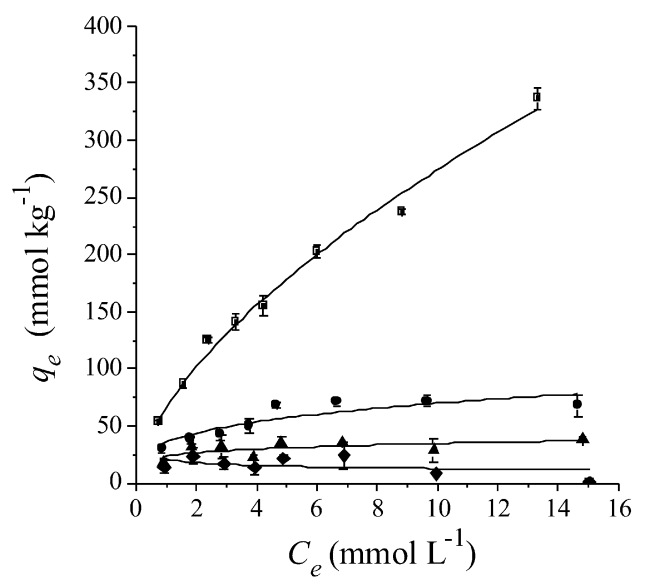

(a)

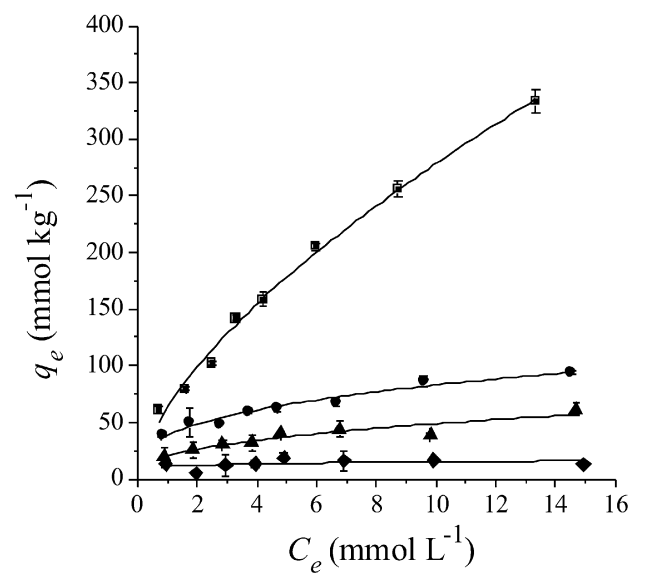

(c)

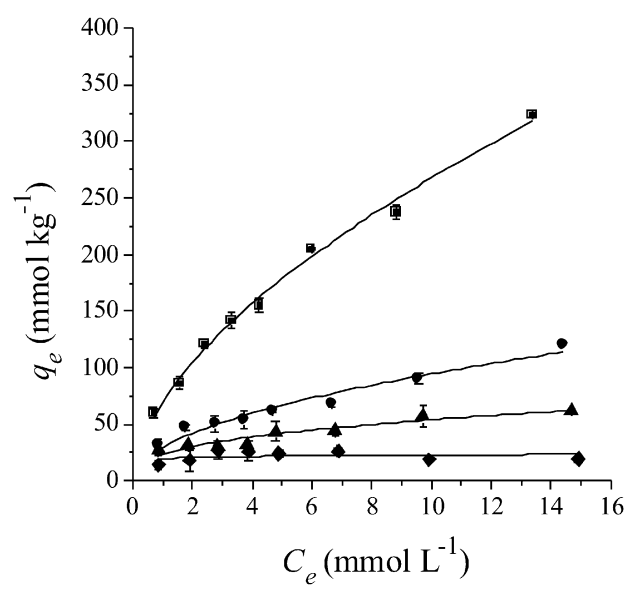

(e)

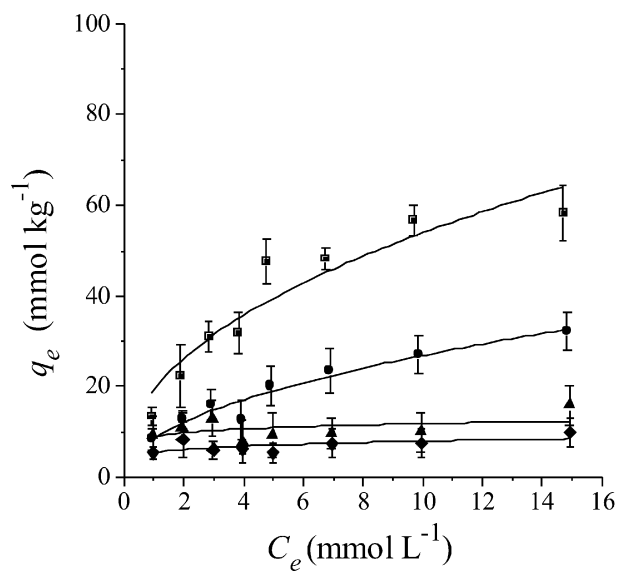

(b)

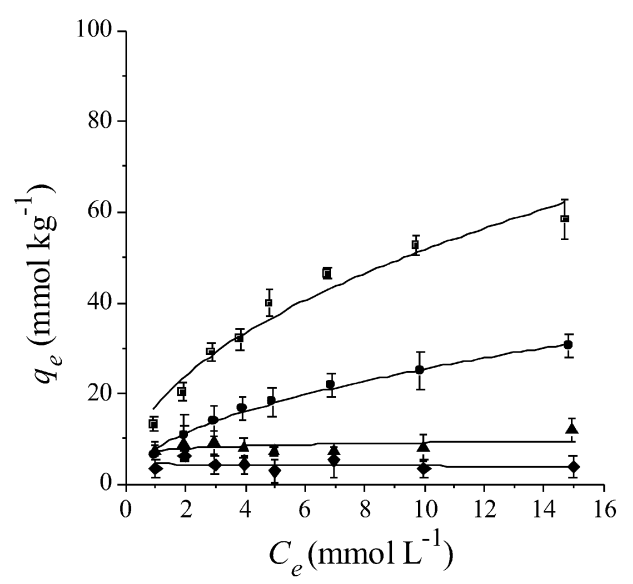

(d)

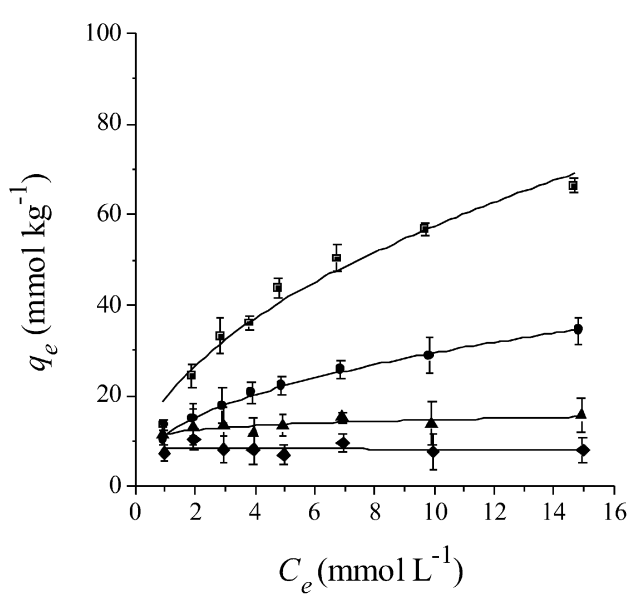

(f)

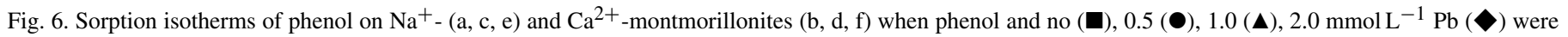
sorbed simultaneously $(\mathrm{a}, \mathrm{b})$, and when $\mathrm{Pb}(\mathrm{c}, \mathrm{d})$ or phenol $(\mathrm{e}, \mathrm{f})$ was previously sorbed.

cept the data of HDTMA-Na ${ }^{+}$-montmorillonite. The sorption capacity of $\mathrm{Pb}$ decreased as follows: $\mathrm{Na}^{+}->\mathrm{Ca}^{2+}->$ HDTMA-Ca ${ }^{2+}$ - > HDTMA-Na ${ }^{+}$-montmorillonites. More $\mathrm{Pb}$ was sorbed onto homoionic montmorillonites than HDTMAmontmorillonites mainly due to the relatively higher cationexchange capacity of $\mathrm{Na}^{+}$-montmorillonite $\left(89.6 \mathrm{cmol} \mathrm{kg}^{-1}\right)$ and $\mathrm{Ca}^{2+}$-montmorillonite $\left(72.4 \mathrm{cmol} \mathrm{kg}^{-1}\right)$ and hydrophobic- ity of HDTMA-montmorillonites. However, the presence of phenol had little effect on $\mathrm{Pb}$ sorption.

Generally, the sorption of $\mathrm{Pb}$ on montmorillonites was very rapid and reached equilibrium within about $1 \mathrm{~h}$. However, the diffusion velocity of phenol was slower than that of $\mathrm{Pb}$ and the sorption equilibrium time was about $18 \mathrm{~h}$. Furthermore, the intensity of coordination bonds between $\mathrm{Pb}$ and montmo- 
Table 3

Freundlich and Langmuir constants and correlation coefficients of sorption of $\mathrm{Pb}$ in the absence and presence of phenol

\begin{tabular}{|c|c|c|c|c|c|c|c|c|c|}
\hline \multirow[t]{2}{*}{ Model } & \multirow[t]{2}{*}{ Parameter } & \multicolumn{2}{|l|}{$\mathrm{Na}^{+}-\mathrm{Mt}^{\mathrm{a}}$} & \multicolumn{2}{|l|}{$\mathrm{Ca}^{2+}-\mathrm{Mt}^{\mathrm{a}}$} & \multicolumn{2}{|c|}{ HDTMA-Ca ${ }^{2+}-\mathrm{Mt}^{\mathrm{a}}$} & \multicolumn{2}{|c|}{ HDTMA-Na ${ }^{+}-\mathrm{Mt}^{\mathrm{a}}$} \\
\hline & & Absence & Presence & Absence & Presence & Absence & Presence & Absence & Presence \\
\hline \multirow{3}{*}{$\begin{array}{l}\text { Freundlich } \\
\text { equation }\end{array}$} & $K_{\mathrm{f}}^{\mathrm{b}}$ & 483.8 & 474.5 & 387.2 & 391.3 & 285.6 & 279.4 & 154.2 & 149.2 \\
\hline & $n$ & 0.3338 & 0.3221 & 0.2869 & 0.2852 & 0.3834 & 0.3894 & 0.7774 & 0.7950 \\
\hline & $R^{2}$ & $0.9825^{c}$ & $0.9784^{\mathrm{c}}$ & $0.9633^{\mathrm{c}}$ & $0.9688^{c}$ & $0.9609^{c}$ & $0.9592^{\mathrm{c}}$ & $0.9874^{\mathrm{c}}$ & $0.9883^{\mathrm{c}}$ \\
\hline \multirow{3}{*}{$\begin{array}{l}\text { Langmuir } \\
\text { equation }\end{array}$} & $q_{\mathrm{m}}\left(\mathrm{mmol} \mathrm{kg}^{-1}\right)$ & 615.0 & 601.3 & 514.7 & 517.1 & 451.5 & 447.2 & 647.7 & 672.9 \\
\hline & $b\left(\mathrm{~L} \mathrm{mmol}^{-1}\right)$ & 6.583 & 6.929 & 6.110 & 6.341 & 2.873 & 2.744 & 0.3571 & 0.3657 \\
\hline & $R^{2}$ & $0.9811^{\mathrm{c}}$ & $0.9823^{\mathrm{c}}$ & $0.9528^{\mathrm{c}}$ & $0.9598^{\mathrm{c}}$ & $0.9325^{\mathrm{c}}$ & $0.9337^{\mathrm{c}}$ & $0.7773^{\mathrm{c}}$ & $0.7140^{\mathrm{c}}$ \\
\hline
\end{tabular}

a Mt, montmorillonite.

b $\left(\mathrm{mmol} \mathrm{kg}^{-1}\left(\mathrm{mmol} \mathrm{L}^{-1}\right)^{-n}\right)$.

c Indicates the statistical significance at probability level of $p<0.01$.

rillonites was also stronger than that of hydrogen bonds and van der Waals force between phenol and sorbents. This may be the reason why the phenol sorption was influenced by addition of $\mathrm{Pb}$, while the sorption of $\mathrm{Pb}$ was independent of phenol on montmorillonites. For HDTMA-montmorillonites, $\mathrm{Pb}$ and phenol were sorbed by different domains, thus their sorption interactions were insignificant.

\section{Conclusions}

The sorption of phenol onto $\mathrm{Na}^{+}$- and $\mathrm{Ca}^{2+}$-montmorillonites was largely decreased in the presence of $\mathrm{Pb}$, while phenol had little effect on the sorption of $\mathrm{Pb}$. For HDTMA- $\mathrm{Na}^{+}$- and HDTMA- $\mathrm{Ca}^{2+}$-montmorillonites, $\mathrm{Pb}$ had little effect on the sorption of phenol and vice versa. The kinetic data can be best described by the pseudo-second-order equation. Sorption of phenol and $\mathrm{Pb}$ onto homoionic and HDTMA-exchanged montmorillonites followed Freundlich equation well. Sorption of phenol on $\mathrm{Na}^{+}$- and $\mathrm{Ca}^{2+}$-montmorillonites was nonlinear and the sorption capacity was relatively low. Due to the interlayer cation exchanging by HDTMA cation surfactant, the sorption of phenol to HDTMA-Na ${ }^{+}$and HDTMA$\mathrm{Ca}^{2+}$-montmorillonites was greatly increased and the sorption isotherms were linear. However, HDTMA-Na ${ }^{+}$- and HDTMA$\mathrm{Ca}^{2+}$-montmorillonites had lower sorption capacity of $\mathrm{Pb}$ than that of $\mathrm{Na}^{+}$- and $\mathrm{Ca}^{2+}$-montmorillonites.

\section{Acknowledgment}

This work was funded by the National Natural Science Foundation of China (Grant No. 20237010).

\section{References}

[1] F.A. Banat, B. Al-Bashir, S. Al-Asheh, O. Hayajneh, Environ. Pollut. 107 (2000) 391.

[2] R.-S. Juang, S.-H. Lin, K.-H. Tsao, J. Colloid Interface Sci. 254 (2002) 234.

[3] Y.-H. Shen, Water Res. 36 (2002) 1107.

[4] S. Al-Asheh, F. Banat, L. Abu-Aitah, Sep. Purif. Technol. 33 (2003) 1.

[5] M. Akçay, G. Akçay, J. Hazard. Mater. B 113 (2004) 189.

[6] N. Yılmaz, S. Yapar, Appl. Clay Sci. 27 (2004) 223.

[7] S. Yapar, V. Özbudak, A. Dias, A. Lopes, J. Hazard. Mater. 121 (2005) 135.

[8] L. Zhu, B. Chen, S. Yu, Environ. Sci. Technol. 32 (1998) 3374.
[9] J.-Q. Jiang, C. Cooper, S. Ouki, Chemosphere 47 (2002) 711.

[10] J.-Q. Jiang, Z. Zeng, Chemosphere 53 (2003) 53.

[11] L. Yang, Z. Zhou, L. Xiao, X. Wang, Environ. Sci. Technol. 37 (2003) 5057.

[12] Y.-H. Shen, Colloids Surf. A 232 (2004) 143

[13] S.A. Boyd, J.-F. Lee, M.M. Mortland, Nature 333 (1988) 345.

[14] S.A. Boyd, M.M. Mortland, C.T. Chiou, Soil Sci. Soc. Am. J. 52 (1988) 652.

[15] S.A. Boyd, S. Sun, J.-F. Lee, M.M. Mortland, Clays Clay Miner. 36 (1988) 125.

[16] W.F. Jaynes, S.A. Boyd, Soil Sci. Soc. Am. J. 55 (1991) 43.

[17] J.A. Smith, P.R. Jaffe, C.T. Chiou, Environ. Sci. Technol. 24 (1990) 1167.

[18] L. Zhu, B. Chen, X. Shen, Environ. Sci. Technol. 34 (2000) 468.

[19] L. Zhu, B. Chen, Environ. Sci. Technol. 34 (2000) 2997.

[20] D.G. Strawn, D.L. Sparks, J. Colloid Interface Sci. 216 (1999) 257.

[21] E. Morillo, C. Maqueda, Sci. Total Environ. 123/124 (1992) 133.

[22] E. Morillo, C. Maqueda, M. Bejarano, L. Madrid, T. Undabeytia, Chemosphere 28 (1994) 2185.

[23] E. Morillo, T. Undabeytia, C. Maqueda, Environ. Sci. Technol. 31 (1997) 3588.

[24] C. Maqueda, T. Undabeytia, E. Morillo, J. Agric. Food Chem. 46 (1998) 1200.

[25] J.-J. Lee, J. Choi, J.-W. Park, Chemosphere 49 (2002) 1309.

[26] G. Sheng, S. Xu, S.A. Boyd, Soil Sci. Soc. Am. J. 63 (1999) 73.

[27] E. Morillo, T. Undabeytia, C. Maqueda, A. Ramos, Chemosphere 47 (2000) 747

[28] E. Morillo, T. Undabeytia, C. Maqueda, A. Ramos, Chemosphere 40 (2002) 103.

[29] Z. Pei, X. Shan, T. Liu, Y. Xie, B. Wen, S. Zhang, S.U. Khan, Environ. Toxicol. Chem. 25 (2006) 2584.

[30] Z. Pei, X. Shan, B. Wen, S. Zhang, L. Yan, S.U. Khan, Environ. Pollut. 139 (2006) 541.

[31] Y.-S. Ho, J. Hazard. Mater. B 136 (2006) 681.

[32] Z. Li, T. Burt, R.S. Bowman, Environ. Sci. Technol. 34 (2000) 3756.

[33] S.B. Haderleln, R.P. Schwarzenbach, Environ. Sci. Technol. 27 (1993) 316.

[34] P.X. Wu, Z.W. Liao, H.F. Zhang, J.G. Guo, Environ. Int. 26 (2001) 401.

[35] Y.S. Ho, Scientometrics 59 (2002) 171.

[36] A. Jain, V.K. Gupta, S. Jain, Suhas, Environ. Sci. Technol. 38 (2004) 1195.

[37] M. Akçay, J. Colloid Interface Sci. 280 (2004) 299.

[38] A. Kuleyin, J. Hazard. Mater. (2006), doi:10.1016/j.jhazmat.2006.10.036.

[39] R.-S. Juang, F.-C. Wu, R.-L. Tseng, J. Colloid Interface Sci. 227 (2000) 437.

[40] M. Sathiskumar, A.R. Binupriya, D. Kavitha, S.E. Yun, Bioresour. Technol. 98 (2007) 866.

[41] Z. Reddad, C. Gerente, Y. Andres, P.L. Cloirec, Environ. Sci. Technol. 36 (2002) 2067.

[42] R.P. Schwarzenbach, P.M. Gschwend, D.M. Imboden, Environmental Organic Chemistry, Wiley, Hoboken, NJ, 2003.

[43] G. Sheng, S. Xu, S.A. Boyd, Environ. Sci. Technol. 30 (1996) 1553.

[44] S.K. Dentel, J.Y. Bottero, K. Khatib, H. Demougeot, J.P. Duguet, C. Anselme, Water Res. 29 (1995) 1273. 